\title{
Fichte, o la revolución aborigen permanente
}

\author{
Jean-Christophe Goddard
}

Traductor: Francisco Antuña

\section{OpenEdition \\ Journals}

Edición electrónica

URL: http://journals.openedition.org/ref/294

DOI: $10.4000 /$ ref.294

ISSN: 2258-014X

Editor

EuroPhilosophie Editions

Referencia electrónica

Jean-Christophe Goddard, «Fichte, o la revolución aborigen permanente », Revista de Estud(i)os sobre Fichte [En línea], 4 | 2012, Publicado el 01 septiembre 2012, consultado el 08 septiembre 2020. URL : http://journals.openedition.org/ref/294; DOI : https://doi.org/10.4000/ref.294

Este documento fue generado automáticamente el 8 septiembre 2020.

(c) EuroPhilosophie 


\title{
Fichte, o la revolución aborigen permanente
}

\author{
Jean-Christophe Goddard
}

Tradución : Francisco Antuña

\section{NOTA DEL EDITOR}

Traducción: Francisco Antuña. Sobre esta traducción, debe tenerse en consideración técnica que, si bien se ha procurado la mayor literalidad para no traicionarlo o retorcer demasiado el texto original, a) dentro del cuerpo del texto se incluye -en ciertas ocasiones- alguno que otro conector o término entre corchetes [], y b) que las notas referidas al pie -con signos numéricos arábigos- pertenecen al autor, mientras que las notas al final del texto -signadas dentro del cuerpo por i, ii, etc.,- pertenecen al traductor, en virtud de aclarar ciertas dificultades para la lengua castellana. A propósito del esclarecimiento de esas dificultades con el francés, quiero agradecer particularmente a Frédéric Bartholin. También quiero agradecer a Emiliano Acosta por la lectura previa y atenta a la publicación de este texto.

1 Al comienzo del séptimo discurso a la nación alemana, Fichte expresa algo muy singular, que a condición de que se lo tome por serio - ¿y por qué no se lo tomaría por serio?- arroja una nueva iluminación acerca de su obra conjunta. Se trata, una vez más, de la diferencia ontológica que sostiene los dos puntos de vista científicos del dogmatismo y del trascendentalismo. Dos puntos de vista, propuestos por libre elección, que no son de ningún modo dos maneras posibles de ver respecto de un mismo ser, sino dos vías separadas, dos ópticas correspondientes a dos seres -por así decir- específicamente distintos. Dos perspectivas, no en el sentido perspectivista y relativista de una variedad de observaciones [vues] sobre lo mismo, sino en el sentido de dos ideas [visions], dos producciones de saber o conciencia, que entablan una diferencia sobre las cosas, considerándolas en sí mismas: de tal modo, que no se podría cambiar de perspectiva; ver lo que el otro ve más que a condición de transformarse en el otro, de devenir propiamente otro ser. No otro ser, en el sentido de una misma humanidad, sino 
el ser de otra humanidad. Es así que hay que comprender el: «Solltest du anders sehen, so müsstest du erst anders werden» " ("para ver de otra manera, debes primeramente devenir otro») del séptimo discurso; vinculándolo a la cadena de enunciados que, por medio de la obra, oponen dos humanidades, antigua y moderna, prioritaria y no prioritaria, etc., no como división histórica o como división social, sino como diferencia de ser.

2 El problema que se establece y que debe resolver la Wissenschaftslehre, en cuanto que práctica de iniciación (Anweisung) de una nueva vida (de la filosofía trascendental) es, pues, un problema de transformación, de devenir; el del paso de un ver a otro ver, como al ver de otra especie, de otro ser. La dificultad que se asigna el Wissenschaftslehreri, en la medida en la que él tiene que conducir esta iniciación, será pues: la de encontrar la vía de una continuidad real entre los dos términos polarizados y no homólogos -que no son sino las dos humanidades-, la de des-polarizar prácticamente su polaridad ontológica. La filosofía trascendental no es en absoluto -como se ha creído y se cree siempre de una u otra manera- una doctrina cuyo valor se mediría según el rasero de las esperanzas de la razón especulativa; ella es indisociable de aquella experiencia de des-polarización y transformación, que nada tiene que ver con la especulación y responde a otras fuerzas.

3 Al inicio del séptimo discurso a la nación alemana, la diferencia atropo-ontológica opone el ser íntimo del Ausland a aquel del Urvolk. Dos términos que es preciso traducir literalmente si se quiere evitar toda complicación ideológica inútil. El Ausland designa lo que está situado fuera del país; el Urvolk designa el pueblo nativo, aborigen. La misma polaridad se estructura en el acontecimiento que constituye la invasión del territorio mediante una potencia exterior y la sujeción de los nativos, por parte de los invasores. Ella es originariamente la expresión de una relación de dominación.

4 Pero adquiere también una dimensión esencial -como prueba de que la invasión no sólo reviste el carácter de un acontecimiento contingente, sino que entabla una diferencia más radical, el pensamiento implicado por el acontecimiento flotante e indeciso, entre contingencia histórica y determinaciones inmutables, acontecimiento y estructura, de modo equidistante-: el invasor, el Ausland, puesto que viene del exterior del Land para conquistar, es también la Nichtursprunglichkeit, la negación del principio aborigen. Es, por su esencia, no-nativo, no en el sentido en que vendría de otra parte, ${ }^{\text {ii }}$ o tendría un origen geográfico diferente, sino porque es ontológicamente extranjero a toda génesis, a toda mediación; es -para utilizar un lexema fichteano- sin «Durch».iii El invasor jamás proviene de algún lado. Por el hecho brutal de su acto de invasión anula toda proveniencia, toda primitividad o querencia [nativité]; no posee otra existencia más que la factual.

5 Por lo contrario, el Urvolk designa el pueblo, todo pueblo, en la medida en que para ser un pueblo debe ser necesariamente nativo, originario, primitivo, en cuanto ${ }^{\text {iv }}$ que en su ser no es solamente «factual»o «histórico», como lo es aquel de una armada colonial o imperial de conquista, o de una administración estatal, etc., sino "genético». Esto es, está integralmente constituido por las mediaciones simbólicas a través de las cuales se imagina y se forma (sich bildet) él por él mismo (la noción fichteana de génesis, vaciada de toda significación genealógica).

6 Pues, los términos polares no son simétricos: si el Ausland se constituye a partir del traspaso de una frontera exterior mediante un ejército imperial, el Urvolk, el aborigen no se comprende relativamente por una frontera exterior, sino «interior». Si el aborigen es el primer habitante, no lo es en el sentido en que sus ancestros serían los primeros ocupantes del lugar circunscrito por sus fronteras naturales. «Primer» califica 
más bien la manera del que habita el lugar -y «habitar» no es «ocupar». La habitación [habitation] $]^{v}$ es lo primero, y el Urvolk es un primer pueblo, en el sentido de que el lugar, el territorio que forma su nación, propiamente se engendra por su habitación. Esta habitación, contrariamente a la ocupación militar estatal que se apropia una extensión natural violando la frontera exterior, no es extensiva, sino intensiva. No basta con decir que la frontera interior es lingüística, espiritual y moral; también es preciso añadir, como lo ha percibido notablemente Etienne Balibar, que la vida original del pueblo -su vida lingüística, espiritual y moral- es esencialmente «el movimiento de una formación continuada (Bildung), de una actividad práctica (Tätigkeit), de una superación de todo aquello que es dado, y determinado como dado (Etwas)»: «una revolución interior permanente».

7 De este modo, no basta con decir que la noción de Urvolk está vaciada de todo contenido naturalista; hay que señalar aún, y más radicalmente, que ella rompe pura y simplemente con la ontología naturalista moderna en la medida en que se definiría por la oposición de la exterioridad física común y de la pluralidad de interioridades psíquicas: la polaridad de la frontera exterior y de la frontera interior no tiene propiamente nada que ver con cierto corte [coupure] de lo físico y de lo psíquico. La interioridad del pueblo aborigen no es una intimidad inviolable por la fuerza armada de los conquistadores, porque ella se situaría, más allá de la existencia física, sobre un plano de ser en que la violencia material no tiene efecto [est sans prise]. Su interioridad, su «in sich», no se comprende como retrato en sí o superación de la existencia mundana, sino al contrario, como compromiso práctico, como afirmación del primado de la existencia práctica en este mundo. La interioridad del pueblo aborigen es autoformación continua de sí; ella se hace uno [fait une avec] con su ser integralmente primitivo, genético. $Y$ esta autoafirmación es indisociable de su actividad práctica, es decir, de sus prácticas, que se pueden llamar «inmateriales» solamente en la medida en que ellas constituyen lo que se denomina «un patrimonio inmaterial», o igualmente, una cultura simbólica viviente en perpetua transformación, que no se deja petrificar [figer] ni transmitir bajo ningún decreto. Como conjunto de prácticas inmateriales y simbólicas, la interioridad aborigen realiza, en cada uno de sus actos, la unidad inmediata de lo físico y de lo psíquico.

Desde este punto de vista, es notable y perfectamente coherente que la Wissenschaftlehre, la enseñanza de la vida, dispensada por Fichte a los filósofos, se niegue explícitamente a convertirse en un «libro», siendo que su transmisión oral -así como la escucha del tiempo que dura la lección- es la misma condición sine qua non de su comprensión y de su eficacia. Amigos o enemigos, si los escritores-filósofos que han escrito sobre la Wissenschaftlehre no han podido elevarse hasta el concepto que hay en Fichte, es precisamente porque son escritores y han escrito sobre ella. ${ }^{2}$ Sólo los oyentes de la Wissenschaftlehre, en la medida en que no han escrito («die aber nicht geschrieben»), son susceptibles, según Fichte, de acceder no solamente al concepto que tiene él mismo, sino a un concepto de la Wissenschaftlehre más elevado que el suyo. Hay una declaración que merecería ser reflexionada con seriedad por los estudios fichteanos, puesto que obliga a reconsiderar el estatuto del texto sobre el cual se apoya el sabio comentario de la Wissenschaftlehre: [se trata] del trazo escrito de un resultado [performance] oral, necesariamente oral, que no sobrevive en ningún texto, sino más bien en su repetición oral, [sea] por el Wissenschaftlehrer o [sea] por sus oyentes. ${ }^{\mathrm{vi}}$ 
Es esto lo que explica la serie de las repeticiones incesantes de la exposición fichteana; de año en año, en ocasiones hasta varias veces en un mismo año, pero no tanto como una re-estructuración incesante de lo mismo, o de aproximaciones sucesivas más o menos acabadas de una misma realización, sino más bien como práctica continua de una obra oral, esencialmente inestable, imperfecta, inacabada. Porque ella rechaza la estabilidad y el acabamiento esperados por la ciencia doctrinal que, en beneficio de las instituciones académicas, se preocupa por proporcionar una representación histórica, integralmente comunicable por escrito (schriftlich) del acontecimiento del pensamiento que es el pensamiento filosófico.

De un modo general, para hablar correctamente de Fichte convendría abandonar todos los falsos problemas artificialmente construidos por la crítica erudita, que dan a la obra una dimensión histórico-factual: el de la unidad o no unidad de la doctrina -de su evolución o de sus recambios a través de las diferentes secuencias de su producción (período de Jena, período intermediario, período tardío)-; el de su filiación al trascendentalismo kantiano o a la mística renana; el de su pertenencia al campo revolucionario o al campo reaccionario, etc. La Wissenschaftslehre es sin historia. Reducida a su dimensión práctico inmaterial -es decir a lo que hemos identificado como su dimensión aborigen- la Wissenschaftslehre, o más bien las múltiples Wissenschaftslehre en que ella consiste, se trata de recorridos únicos, inconmensurables, integralmente generados a partir de problemas que proporcionan sus impulsos para las experimentaciones activas, dinámicas y colectivas.

11 La Wissenschaftslehre no se deja reducir a los esquemas o estructuras finitas. Obviamente que no deja de recurrir a diagramas, pero sus esquemas (del tipo ${ }^{3} \mathrm{xyz} .{ }^{\mathrm{A}} \mathrm{SD}, \mathrm{B}-\mathrm{L}-\mathrm{S}$, etc.) no son las formas estáticas que organizan los contenidos de una doctrina para facilitar su interpretación. Como formas fluyentes, intuitivas, engendradas en el pasaje trasespecífico de un ver a otro ver, los diagramas no subsisten más allá del momento en que, en el curso de la lección, exigen una visión colectiva de auto-afirmación continua. $\mathrm{Su}$ significado debe permanecer vago, indeciso, y la atención que lo dirige debe ser como aquella que se da en los esbozos [ébauches], abierta a su metamorfosis futura, portadora de una visión diferente; lo esencial permanece aquí como la transformación de un ver, que es indisociable de devenir otra cosa. Los esquemas, las imágenes y los diagramas movilizados por la Wissenschaftslehre son, en realidad, más bien acontecimientos que estructuras; engendrados por la experiencia de transformación antropo-ontológica en que consiste la Wissenschaftslehre, expresan la relación de fuerzas que están presentes en esa experiencia -la tensión de lo vital y de lo letal, de lo centrípeto y de lo centrífugo, etc.-, y revisten inmediatamente una dimensión dramática. Son los acontecimientos con los cuales se construye la estructura inestable, genética, del relato por el cual la Wissenschaftslehre trata de mantener su promesa, que consiste en hacer ver cosas aún jamás vistas.

12 Movimiento de una formación continuada; palabra viva esencialmente itinerante, que crea [fait] una historia y no tiene historia, que debe ser comprendida en el momento que ella la crea; conversión del espacio constituido (de la escritura y de la institución académica de los saberes) en un tiempo constituyente, es decir que, a futuro -y a tal punto que, comprenderla consista pura y simplemente en practicarla a través de la repetición de un proceso ambulante, de una nueva itineración colectiva- la Wissenschaftslehre presenta los caracteres del pensamiento aborigen. Difícilmente se ha comprendido el sentido del Soll («debe») ${ }^{\text {vii }}$ que condiciona el conjunto de su marcha; 
significa su carácter experimental, su modo exclusivamente problemático, la imposibilidad de reducir sus enunciados a una axiomática o aparato categórico, a partir de los cuales podrían ser reiterados independientemente los problemas singulares a los que responden y que surgen al hilo de la misma experimentación.

Desde este punto de vista es notable que el comentario académico de la Wissenschaftslehre se afane en formalizar la exploración mediante la evolución [cheminement]. El flujo de imágenes por medio del cual se practica esta exploración, sometiéndolas a su modelo de inteligibilidad de esencia estática, formalizándolas, recortándolas en secuencias sucesivas y forjando con esos fragmentos el falso problema-pantalla [problème-écran] se convirtió en la cruz de los intérpretes, y en el número exacto de secuencias identificables. Para semejante captura [capture] académica no hay otra vía más que la de invertir el modelo aborigen y substituirlo por el remiendo [bricolaje] experimental que consiste en fabricar de la estructura (anexacta) y del acontecimiento la construcción de una estructura (exacta) susceptible de hacer historia. Es decir, no de hacer una historia (la de un grupo, de una subjetividad colectiva inestable, de una tribu (Stamm) o de una minoría), sino de hacer acontecimiento en la historia universal de la filosofía. Felizmente, tal tentativa ha fracasado siempre, más o menos siempre y la Wissenschaftslehre, pasaje obligado para todos los historiadores y antologistas del idealismo alemán, permanece, pese a todos los esfuerzos academicistas, como una contribución marginal, difícilmente asimilable a la historia del pensamiento.

14 La antropología del Discurso a la nación alemana permite comprender mejor en qué medida la Wissenschaftslehre es embarazosa para la historiografía universitaria de la filosofía. En el momento que se funda la historia intelectual de Europa contemporánea (en el momento de uno de sus más potentes movimientos de universalización) la Wissenschaftslehre es testigo de una forma de pensamiento híbrido que, en el cuadro de una producción universitaria y en el contexto de un amplio programa de reorganización de las formas de racionalidad occidental, realiza los caracteres de un pensamiento primitivo o salvaje: la pluralidad de las humanidades y la perspectiva inter-específica, la potencia genética de la imagen no representacional y colectiva, el remiendo de estructuras inestables por medio de los acontecimientos. Estos caracteres fueron identificados por la etnología contemporánea como distintivos de ciertas operaciones -respectivamente: del sacrificio (Viveiros de Castro), de la tecnología del sueño (Glowczewski), de la mitogénesis (Levi-Strauss)- que además han sido observados sobretodo en ciertos pueblos indígenas, amerindios o australianos. Pero, de manera general, no es sorprendente que tales procesos -que por otra parte han adquirido en estos pueblos la forma de prácticas tan complejas y sutiles como aquella de la Wissenschaftslehre- puedan prosperar en nuestros entornos templados, en los que la modernidad jamás ha sido otra cosa que una constitución (Latour) destinada a combatir nuestras propias hibridaciones y notablemente todas aquellas que no han podido estar ausentes [manquer de résulter] en la aventura colonial. Para nosotros, sólo cuenta aquí la reivindicación singular de la obra-Fichte, de las operaciones tanto similares como susceptibles de liberar el pensamiento de la dominación del modelo ontológico (dogmático) adoptado, casi sin excepción, por toda la filosofía occidental. 

alemana, se distinguen efectivamente los principales caracteres de la filosofía occidental. En ese discurso, la noción de Ausland ya está íntimamente conectada a un principio de territorialidad: su esencia (Wessen) es, dice Fichte, la de creer en la existencia de una frontera infranqueable, que separa cualquier término último, fijo y cerrado, del libre juego fluyente [fluent] de la vida, hasta el punto de no poder creer ni pensar [absolutamente] nada sin presuponer esa frontera. En sentido contrario a la frontera interior que define la identidad exclusivamente genética -en devenir- del pueblo aborigen, la frontera ontológica presupuesta por el Ausland está ahí, ante todo, para preservar lo inmutable del desbordamiento, del derrame [écoulement] de la vida en [pueblo aborigen] -para preservarla del contagio de muerte (del anquilosamiento original) a favor de la vida. foulant au pied] de la sociabilidad inmanente de los pueblos en nombre de principios universales e inmutables de la Revolución. También la violencia del Ausland, manifiesta en la ocupación militar, se ejerce ante todo sobre los espíritus a través de la divulgación de una doxa, es decir, como ideología. Esta ideología mortífera, de esencia paranoica, que opone la identidad intangible de un objeto total y estático («ein Stehendes», «ein festes Sein») al libre flujo de las diferencias, se expresa igualmente, e independientemente de la empresa militar napoleónica, en la mejor producción filosófica alemana contemporánea de los Discursos a la nación alemana: bajo la influencia del Ausland, sometida al atractivo de lo Inmóvil -aspirante a la inercia-, aquella [producción], nota Fichte, «quiere» (will) la forma científica, el fundamento inmóvil (Grundlage) sobre el cual reposa. Bajo todos estos puntos, [como] fuerte de esta voluntad de inmovilidad, y sacando provecho de los progresos ya cumplidos por el Ausland, la filosofía alemana gana razón (hat recht) viii y supera con mucho a la filosofía dominante del Ausland, siendo más profunda y consecuente en materia de Ausländerei, llevando la sujeción lejos de la que se da en un contexto colonial, donde, habiendo abandonado sus propias prácticas, lo colonizado sobresale a las prácticas del colonizador. La vida no se sostiene más por sí misma, como lo hace en su propia dimensión aborigen. De este modo, sujetada por la misma sujeción, de la que por otra parte se sujeta el colonizador, se preocupa sobre todo en asignar a la vida un «portador» (Träger) y un «sostén» (Stütze). La filosofía, alienada por la necesidad de ser portada, impone autoritariamente, a quien se baste de la vida, la necesidad de tal portaje (portage). ${ }^{\text {ix }}$

17 A ella se opone la filosofía verdadera que, advenediza hasta el extremo de sí misma, ha penetrado el «núcleo» (Kern) del fenómeno y procede de la vida divina «una y pura». Es decir, no de la vida unificada bajo un principio -la vida contenida más acá de la frontera, que retiene su flujo amenazador de infiltrar su propio sustrato inmóvil-, sino de la vida en cuanto que simple vida (als Leben schlechtweg), que permanece siempre una, es decir «una vida», sin ser la vida de tal o cual individuo -la vida de un sujeto formado, estable- y [que] consiste en el latido rítmico constante de una apertura y cierre, de una arsis y una thesis, de una determinación y de una indeterminación, para que se ejerza la actividad formadora continua; el infinito sich bilden del pueblo aborigen.

La filosofía alemana, que estamos habituados a considerar como la filosofía alemana y a la que vemos como ejemplar de la emergencia de una filosofía nacional a principios del siglo XIX, es en realidad lo que hay de menos alemán: un pensamiento extranjero enteramente subordinado al prestigio de lo Inmóvil y a lo que este ídolo exige de ella, lo 
que en el cuarto capítulo de la Evolución Creadora, Bergson identifica como un síndrome griego-; un pensamiento negador de toda vida nacional propiamente dicha, es decir, de la vida de una nación sin Estado, idéntica a la invención simbólica permanente del pueblo por sí mismo.

Pero ¿cómo comprender, entonces, que la Wissenschaftslehre, que pretende ser esta filosofía verdaderamente nacional-aborigen, satisfaga, por otra parte, a tal punto las exigencias impuestas por el Ausland (la forma científica, la realización de la unidad, la fundación inmutable de lo mutable, la determinación del ser portador de toda realidad) que ha podido consagrar seriamente obras enteras, al modo en que las completa?

Aquí no basta con inculpar la captura de la Wissenschaftslehre por la institución académica. La Wissenschaftslehre comienza siempre por tratar cuestiones que interesan a los filósofos. Su meta es la de iniciarlos a la vida, y para ella no existe otro medio, ni otra pedagogía que retome desde el principio el proyecto filosófico en los términos que le son propios, para conducirlo hasta el fin de sí mismo. No se des-coloniza el pensamiento sin habitar las estructuras mismas del pensamiento colonizado. La descolonización no reconduce a la existencia aborigen como a la pureza de un estado primitivo accesible por la simple sustracción de todo lo que ha venido a sobreañadirse. Ella es necesariamente un proceso de hibridación. Lo alemán-aborigen [allemandaborigène] que se destaca en la investigación académica de la unidad es ya, en un sentido, un ser mixto. Esta mixtura [mixité] debe hacerse manifiesta, y es a partir de ella que debe ser construida la hibridación descolonial: cumplir, a contrapelo con la excelencia académica, una práctica auténticamente aborigen y no ya ausländisch de la filosofía del Ausland. Y la Wissenschaftslehre es esa práctica, en tanto aplica a las categorías del pensamiento del Ausland un modo a la vez genético, problemático y dramático.

21 La filosofía alienada a la figura trascendente, real, de lo Uno sin vida, encuentra en la Wissenschaftslehre algo que parece a su propia creencia, pero que sin embargo no llega completamente a identificarse con ella. Es que el Wissenschaftslehrer ya no imita a la ciencia real del Ausland, al igual que sus contemporáneos alemanes. Él la ejecuta como se ejecuta un rol, convocando alternativamente las categorías de esa ciencia al modo teatral del «als» (del «como»), a fin de hacerlas entrar en un trance, donde sus pretensiones teoremáticas puestas en jaque [mises en échec] no lleguen ya a formar ningún aparato conceptual durable y cedan frente a la unidad inmanente del fenómeno. La descolonización consiste aquí en tomar los elementos mismos de la ciencia ausländish como soportes de la transformación del ver y de la experimentación del devenir otro. Al igual que pasa con los personajes del cinéma-vérité de Rouch, el Wissenschaftslehrer no dispone de otra cosa más que de los elementos que le suministra el orden colonial para inventarse una identidad simbólica diferente a aquella que le es asignada por este orden; [y] es precisamente con esos [elementos] que él lo tiene que remendar, deambular, experimentar. ${ }^{\mathrm{x}}$ La hibridación activa, practicada por el Wissenschaftslehrer, se aplica a estos únicos elementos. Ella consiste en hibridar al Ausland, en subvertirlo bajo el modelo aborigen -es decir hacerle contribuir con aquello a lo que se opone con todo su ser: la liberación de la simple vida, de la vida salvaje, sin apoyo y que se sostiene por sí. 


\section{NOTAS}

1. Reden an die deutsche Nation, Meiner, 2008, p. 109.

2. Cf. Die Wissenschaftslehre. Zweiter Vortrag im Jahre 1804, Meiner, 1986, p. 135.

3. Expresados en la segunda versión de la Wissenschaftslehre 1804.

\section{NOTAS FINALES}

i. Es usual entre los comentaristas de la obra de Fichte hacer uso del término Wissenschaftslehrer para referirse al mismo Fichte. No obstante, es poco usual traducirlo. Así, para el lector de habla hispana sería importante que lo entienda como "el hacedor de la Doctrina de la Ciencia" y que no lo confunda con el "maestro o educador de la Doctrina de la Ciencia". Esto se ajusta más al pensamiento de Fichte y queda aún más claro si seguimos la lectura que Goddard hace de Fichte. A este respecto, en especial, y siguiendo la Doctrina de la Ciencia de $1804^{\mathrm{II}}$, cabe considerar dos cuestiones 1). La importancia de los conceptos que refieren a la esfera de una actividad y construcción permanentes, «Thun» (hacer) y «Thätigkeit» (actividad), a los que recurre continuamente Fichte y a fuerza de los cuales se explica que cada uno entenderá y hará la $D C$-en la medida en que la re-construya como oyente-activo. Y -ligado obviamente a eso-, 2). valdría recordar al filo de esto aquello que Fichte escribe en el marco de una exposición oral, a saber: “ Ich, E.V., will mit diesem Worte als ein Verstummter und Verschwundener betrachtet sein, und Sie selber müssen nun in meine Stelle treten" (GA II/8, 5) ("Yo, estimada asamblea, quiero con esta palabra ser considerado como alguien mudo y desaparecido, y ustedes mismos tienen que ocupar ahora mi lugar"). Toda esta cuestión debería dejar en claro, entonces, que el Wissenschaftslehrer no sólo es Fichte, sino cada uno -en la medida en que lo consiga por sí mismo; de ahí que Goddard sostenga aquí que: "si los escritores-filósofos que han escrito sobre la Wissenschaftlehre no han podido elevarse hasta el concepto que hay en Fichte, es precisamente porque son escritores -y han escrito sobre ella- y no oyentes".

ii. En el siguiente pasaje notamos una posible errata del autor: "... il est par essence no natif, non pas au sens ou il viendrait d'ailleurs, aurait une autre origine géographique... que corregimos: «... il est par essence no natif, non pas au sens où il viendrait d'ailleurs, aurait une autre origine géographique."

iii. Preferimos mantener la literalidad "est... sans "Durch»"con la que el autor expresa esta carencia de mediación del extranjero, que constituye su "ser".

iv. Variamos la proposición con : "en cuanto que", aunque Goddard usa, en la misma frase, dos veces «dans la mesure où».

v. Guardamos el término que usa Goddard y que antes de ser identificado con "domicilio", "vivienda", debe tenérselo como "fait de résider", como el acto mismo de habitar.

vi. A esta última proposición le hemos añadido ciertos conectores para hacerla más comprensible. La original dice: [...] :trace écrite d'une performance orale, nécessairement orale, qui ne survit dans aucun texte, mais dans sa seule reprise orale par le Wissenschaftslehrer ou par ses auditeurs.

vii. Goddard traduce « Soll » por « il faut» 
viii. Aunque la partícula germana "hat recht" se traduzca por "tiene razón" (Recht haben; im Recht sein = tener razón) Goddard escribe "obtient raison"; de ahí nuestra traducción.

ix. La traducción se ajusta, sin traicionar demasiado el texto original, al juego intencional de palabras, o a una variación terminológica del mismo vocablo que ejecuta el mismo Goddard: 1) "porteur" (portador, mensajero); 2) "porté" (participio pasado del verbo "porter" = llevar, sostener), y luego 3) "portage" (portaje) -en el siguiente pasaje original:

porteur » (Träger) et un «soutien » (Stütze). La philosophie, aliénée au besoin d'être porté, imposant autoritairement à qui se suffit de la vie la nécessité d'un tel portage.

Tomando en cuenta el concepto alemán Stütze (propio de los Discursos... de Fichte) que antecede e implica a esta proposición, también podría traducirse -pero ciertamente perdiendo la secuencia terminológico-francesa-:

... La filosofía, alienada por la necesidad de ser sostenida, impone autoritariamente a quien se baste de la vida, la necesidad de tal sostén.

x. El original dice: «C'est avec eux qu'il lui faut bricoler, ambuler, expérimenter».

\section{RESÚMENES}

In this article the author proposes a new reading of Fichte's Addresses to the German Nation (1808), by means of which he tries to give a new meaning to some of the key concepts of this work such as "Urvolk". This reading, which is as original as subversive, serves the author as starting point for a series of reflections on the spirit of the doctrine of science aimed at recovering the particular potential of Fichte's philosophy, which is usually ignored in the traditional studies of this philosopher.

\section{ÍNDICE}

Keywords: Fichte, Doctrine of Science, Addresses to the German Nation (1808)

\section{AUTORES}

\section{JEAN-CHRISTOPHE GODDARD}

Université de Toulouse le Mirail, ERRAPHIS/EuroPhilosophie 